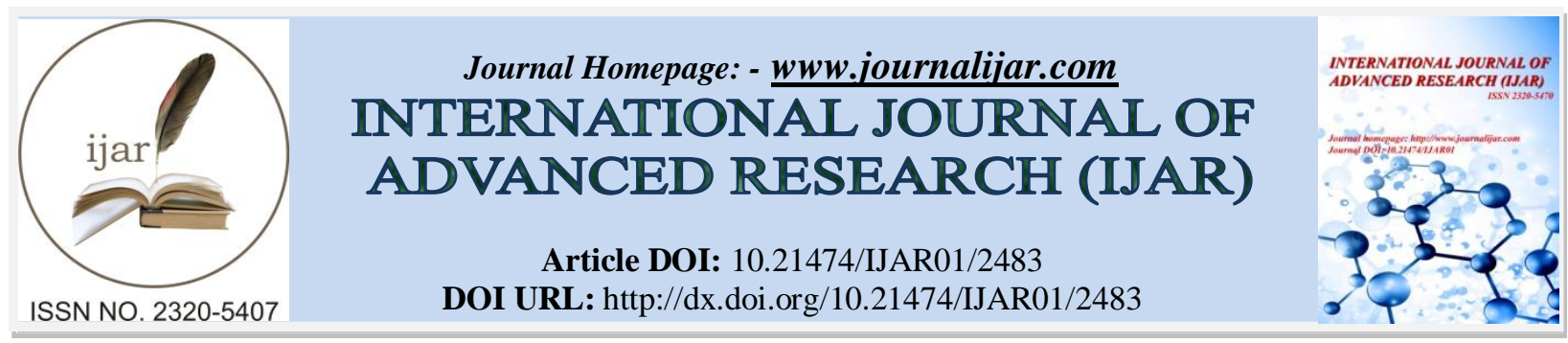

RESEARCH ARTICLE

\title{
OPPORTUNISTIC OCCURRENCE, SIGNIFICANCE AND CONSERVATION IMPLICATIONS OF TRICHO-MORPHOMETRICS: LARGE WILD HERBIVORES OF CHANG CHENMO VALLEY, LADAKH, INDIA.
}

\footnotetext{
"Vinita Sharma 1,3, Mohd. Raza², Khursheed Ahmed², Parag Nigam³, Anjara Anjum Khan', Chandra Prakash Sharma ${ }^{3}$, Vipin Sharma ${ }^{3}$ and Surendra Prakash Goyal ${ }^{3}$.

1. Central University of Jammu, Department of Animal Sciences and Wildlife, Central University of Jammu, Rahya-Suchani (Bagla), District - Samba, Jammu - 181143, Jammu and Kashmir, India.

2. Centre for Mountain Wildlife Sciences, Faculty of Veterinary Sciences and Animal Husbandry, Sher-e-Kashmir University of Agricultural Sciences and Technology, Srinagar, Jammu and Kashmir, India-190006.

3. Wildlife Institute of India, Post Box \# 18, Chandrabani, Dehradun, Uttarakhand, India-248001.
}

\section{Manuscript Info}

Manuscript History

Received: 23 October 2016

Final Accepted: 21 November 2016

Published: December 2016

Key words:-

Tricho-morphometrics, Chang Chenmo

Valley, large wild herbivores,

conservation

\section{Abstract}

Tricho-morphometric studies plays significant role in understanding various aspects of mammalian biology and ecology that have direct conservation implications for species and associated habitats. In the present study, the Chang Chenmo Valley (CCV) region of Changthang Wildlife Sanctuary (CWLS) in the Western Himalayas, India was extensively surveyed during August-October, 2013 to document the occurrence of large wild herbivores. Both direct (sightings) and indirect (calls, faecal pellets, chew and hoof marks, hair, carcasses) evidences were recorded and geo-referenced accordingly. Resting sites, tracks and areas frequently visited by animals were intensively searched for the presence of opportunistically found naturally shed hair which were collected $(n=43)$ for identification of species using tricho-morphometric analysis following established protocols. Five large wild herbivore species, namely the Tibetan Antelope (Pantholops hodgsonii Abel, 1826), the Blue Sheep (Pseudois nayaur Hodgson, 1833), the Tibetan Argali (Ovis ammon hodgsonii Blyth, 1841), the Wild Yak (Bos mutus Przewalski, 1883) and the Tibetan Wild Ass (Equus kiang Moorcroft, 1841) were directly sighted in the CCV region. Simultaneously multispecies assemblages in inhospitable terrain were also confirmed by tricho-morphometric analysis. Habitat conservation is the vital requirement for protecting the species and ecological processes of the entire ecosystem. Therefore, we suggest that hair be collected along with GPS locations when surveys are undertaken for direct evidence. Tricho-morphometric studies from opportunistically found hair provides additional help to understand species ecology, estimating relative abundance, occupancy and in establishing wildlife-habitat relationships which may help in the development of effective conservation policies for restoring unique habitats. 


\section{Introduction:-}

Large wild mammalian herbivores occupy half of the earth's land surface. They are considered as ecological engineers (Owen-Smith, 1988; Dinerstein, 2003; Chane and Yirga, 2014) and play an important role in shaping the structure, diversity and functioning of most of terrestrial ecosystems (Owen-Smith, 1988; Gordon et al., 2004). Although having a major impact on animals land use and habitats of conservation importance significantly, their very survival is threatened by natural and anthropogenic activities worldwide (Ripple et al., 2015). Information on the distribution of species, diversity patterns and wildlife-habitat relationships is crucial for understanding the ecological and evolutionary determinant of spatial heterogeneity in biodiversity (Ricklefs and Schluter, 1993). The distribution of large herbivores is resource dependent (Olff et al., 2002). Rangelands across the world are important for wildlife conservation (Bhatnagar et al., 2007). The Tibetan Plateau (TP) is the highest and largest alpine grassland region in the world. It provides a unique habitat for many globally threatened wildlife species (Foggin, 2000). The TP is an important highland grazing ecosystem (Goldstein and Beall, 1990) supporting the intact assemblage of Pleistocene large wild herbivores (Schaller, 1998; Bhatnagar et al., 2007). It is also one of the most fascinating regions for scientific research (Zeng et al., 2015). Ladakh is the westernmost range of the TP in India. This area supports eight large wild herbivore species (Mallon, 1998; Bhatnagar et al. 2007; Namgail, 2009; Shawl and Takpa, 2009; Namgail et al., 2010). A study of the literature clearly reveals that there is intense competition for resources between wild and domestic herbivores (Prins, 2000; Madhusudan, 2004). Over the last few decades, the survival of several Trans-Himalayan wild herbivores has been severely threatened. These species have undergone local extinctions and range reductions due to various natural and anthropogenic activities (Fox et al. 1991; Mishra et al. 2002; Bhatnagar et al. 2007). Habitat management practices provide aid to conserve, protect and restore the habitat of wild plants and animal species with especial reference to conservation reliant species worldwide. Determining the extent of occurrence (EOO) of conservation-reliant species is the foremost requirement in developing strategies for habitat management on a large scale. Various methods used for determining the EOO, including direct counts and indirect methods such as those involving faecal matter/pellets, have limitations in this inhospitable habitat in discriminating wild species from domestic counterparts. Hair collected using snares/traps has been widely used in EOO determination as well as in occupancy surveys of carnivore species (Long et al., 2011). Naturally shed hair found near resting places of animals can also help to identify and discriminate species using laboratory-based methods. The microstructure of hair is a useful tool in identifying mammals and is increasingly gaining importance in many areas including forensic science, ecology, environmental toxicology, wildlife management, epidemiology, assessment of geographic mobility, archaeology and palaeontology (White 1993; Ashraf et al., 1994; O’Connell and Hedges, 1999; Quadros and Monteiro, 2006).

The Chang Chenmo Valley (CCV) region, in the northern part of Changthang Wildlife Sanctuary (CWLS), along with the Daulet Beg Oldi (DBO) area of Karakoram (Nubra-Shyok) Wildlife Sanctuary (KNSWLS), in Ladakh, Jammu and Kashmir, forms the western-most range of the TP within the administrative boundaries of India. The $\mathrm{CCV}$ region was extensively surveyed for the large wild herbivore species of the TP ecosystem. The survey was based on direct and indirect evidence such as faecal matter, pellets and hair in the present study. Trichomorphometric characteristics (qualitative and quantitative) of five large wild herbivores encountered in the study area were used to identify species and determine the EOO and other conservation implications in CCV. Present and previous studies (Shawl et al., 2011) justify the immediate development of a trans-boundary habitat management action plan that helps conserve the habitat of large wild herbivore species across the TP.

\section{Materials and methods:- \\ Study area}

The study was carried out during August-October, 2013 in CCV (Fig. 1). The study area is a south-western extension of the TP (Alfred et al., 2006; Shawl and Takpa, 2009), located on the border between India and China (Shawl et al., 2011). Geographically, it is situated between $78^{\circ} 07^{\prime} 00^{\prime \prime} \mathrm{E}$ to $79^{\circ} 00^{\prime} 00^{\prime \prime} \mathrm{E}$ longitudes and $33^{\circ} 55^{\prime} 00^{\prime \prime} \mathrm{N}$ to $34^{\circ} 39^{\prime} 00^{\prime \prime} \mathrm{N}$ latitudes. The altitude ranges between 3700 and 5500 metres above the sea level (Sarkar et al., 2008). The area is drained by the Chang Chenmo and Kurgrung rivers (Meinertzhagen, 1927; Shawl and Takpa, 2009; Shawl et al., 2011). It bounded by the Silung Burma on the east, the Silung Yogma on the west, low hills on the north and hill ranges on the south (Shawl and Tapka, 2009; Shawl et al., 2011) (Fig. 1). The area is characterized by steep, rugged mountains, narrow gorges and wide open valleys surrounded by open, rolling sandy mountains in the east and undulating rugged terrain in the north and south. The temperature ranges from $0^{\circ}$ to $30^{\circ} \mathrm{C}$ in summer and from $-10^{\circ} \mathrm{C}$ to $-40^{\circ} \mathrm{C}$ in winter (Mishra and Humbert-Droz 1998). The vegetation of the region is characterized 
as dry alpine steppe (Champion and Seth, 1968). The area falls within Durbuk Block, which was earlier used by the nomadic pastoralists of Phobrang and adjacent areas. The area has representative components of the Ladakh TransHimalayan ecosystem, which is the most fragile and hardy ecosystem, having a unique, diverse and rare assemblage of high-altitude wildlife species (Fox et. al., 1991; Vinod and Sathyakumar, 1999; Rodgers et al., 2000; Namgail, 2009; Shawl and Takpa, 2009). It is an important habitat for the endangered Tibetan antelope outside China (Shawl and Takpa, 2009; Shawl et al., 2011). It also provides a habitat for the Tibetan argali, wild yak, kiang, blue sheep, Himalayan marmot, Tibetan woolly hare, red fox, Tibetan wolf and snow leopard (Meinertzhagen, 1927; Chundawat and Qureshi, 1999; Shawl and Takpa, 2009; Namgail et al., 2010).

\section{Collection of hair samples:-}

Hair found opportunistically stuck on bushes and shed naturally near resting sites and track was collected during the survey. Hair was also collected from carcasses. Fine-tip forceps were used to collect the hair samples, which were transferred to transparent ziplock packets for analysis and geo-referenced accordingly.

\section{Tricho-morphometric analysis:-}

The characteristics of guard hairs are known to differ from one mammalian species to another (Brunner and Coman, 1974; Kondo, 2000). The morphological characteristics of the cuticle and medulla of a guard hair can be used to identify the species (Brunner and Coman, 1974; Kondo, 2000, Taru et al., 2013). The tricho-morphometric approach was used to identify species and assess the presence and assemblage of species in the CCV (Table. 1). All the hair samples $(n=43)$ were macroscopically screened for the presence of guard hairs. At least five guard hairs per sample were analyzed according to established protocols (Sahajpal et al., 2009; Bahuguna et al., 2010). The macroscopic and microscopic hair characteristics were studied to assess the biological origin (Sahajpal et al., 2009; Bahuguna $e t$ $a l ., 2010$ ). Both qualitative and quantitative (macroscopic and microscopic) hair characteristics (Table 2) of each hair were recorded. The colour, shape and texture of each guard hair were noted. The morphological characteristics (cuticular pattern, including the scale margin, scale distance and scale pattern, and medullary patterns) were observed and photo-micrographed using a comparison microscope (Leica DMR). The hair thickness and medulla thickness were determined. The medullary index was calculated using the following formula:

$$
\text { Medullary Index }(\mathrm{MI})=\quad \text { Hair Thickness (MT) }
$$

Hair Thickness (HT)

The observed tricho-morphometric characteristics were compared with those of reference slides in the hair repository of the Wildlife Institute of India, Dehradun. The quantitative data were statistically analysed. A threedimensional scatter plot between HT, MT and MI was generated using SPSS version 19.0 (IBM, 2010).

\section{Results and discussion:-}

A total of five large wild herbivore species were sighted in the CCV during the study period. Four of these belong to the order Artiodactyla and one belongs to the order Perissodactyla (Table 1). All five species are conservationreliant and significant components of the TP ecosystem. The occurrence of these species reveals the conservation importance of the area. The status of a landscape and its ecosystem can be determined by evaluating the distribution pattern of the large herbivores of the area. Guard hairs could be obtained from 39 samples of the 43 hair samples that were collected from CCV. Thus, the success rate of getting dorsal guard hairs for tricho-morphometric analysis from opportunistically found hair samples was $90.7 \%$. The relative frequency of occurrence of hairs of large wild herbivore species in randomly collected hair samples $(\mathrm{n}=39)$ from the CCV region was Equus kiang (74.4\%) > Pantholops hodgsonii $(10.3 \%)>$ Ovis ammon hodgsonii $(7.7 \%)>$ Pseudois nayaur $(5.1 \%)>$ Bos mutus $(2.6 \%)$ (Table 2). Details of the qualitative and quantitative hair characteristics are provided in Table 3. Photo-micrographs of the cuticular scale casts and medullary patterns are shown in Figure 2.

High-altitude mammals have characteristic wavy and kinky hair along with peculiar brittleness (Sahajpal, 2009). Hair of $P$. hodgsonii, $P$. nayaur, $O$. a. hodgsonii and has the characteristics kinks, while these are absent in the hair of B. mutus and E. kiang (Table 3). The cuticle scale margins are crenate in B. mutus and smooth in the other four species (Table 3). The cuticle scales were close in $O$. a. hodgsonii, B. mutus and E. kiang, while they were far apart in $P$. hodgsonii and P. nayaur (Table 3). The value of HT was greatest in $O$. a. hodgsonii, followed by $P$. nayaur, $E$. kiang, $P$. hodgsonii. It was least in $B$. mutus. The value of MT was greatest in hairs of $O$. a. hodgsonii, followed by $P$. nayaur, E. kiang and $P$. hodgsonii, being least in $B$. mutus. The highest value of MI of guard hairs was observed in $P$. hodgsonii and $O$. a. hodgsonii, followed by E. kiang, and the lowest value was in B. mutus. The three- 
dimensional scatter plot generated between HT, MT and MI also shows a distinct demarcation between the hair characteristics of the five large wild herbivore species found study area (Fig. 3).

Our tricho-morphometric studies confirm the presence of five large wild herbivore species, namely the Tibetan antelope ( $P$. hodgsonii), the blue sheep ( $P$. nayaur), the Tibetan argali (O. a. hodgsonii), the wild yak (B. mutus) and the Tibetan wild ass (E. kiang) in the study area. The distinct characteristics allow discrimination of these five species. It is evident from the present study that tricho-morphometry play a significant role in identifying the biological origin of the species and indirectly confirm the presence of species in an area. The results of the present study also support the findings of previous studies (Mallon, 1998; Bhatnagar et al. 2007; Namgail, 2009; Shawl and Takpa, 2009; Namgail et al., 2010). Although some studies have been conducted previously (Mallon, 1998; Bhatnagar et al. 2007; Namgail, 2009; Shawl and Takpa, 2009; Namgail et al., 2010) to assess the assemblage of species, this was the first time an attempt was made using the tricho-morphometric approach.

Figure 1:- Map of Chang Chenmo Valley, Changthang Wildlife Sanctuary, Ladakh, India

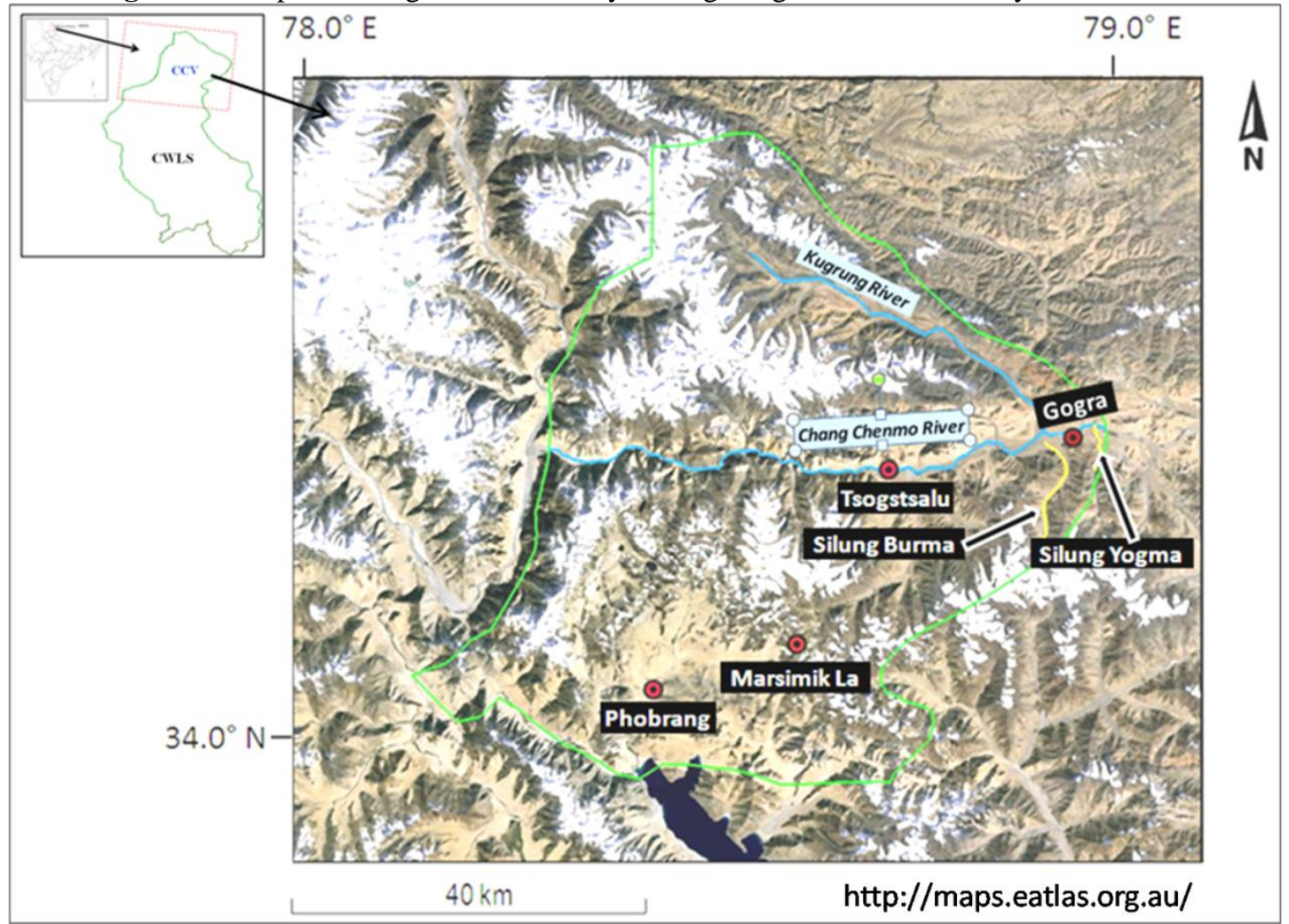

The present study highlights the significance of tricho-morphometry in identifying species from opportunistically found hair samples and assessing the biological diversity of an area. The present study confirms the presence of the species identified and supports the determination of the worldwide distribution range of these threatened species in the TP. Therefore, we suggest hair be collected along with GPS locations during surveys undertaken for direct evidence in inhospitable habitats for subsequent use in estimating the relative abundance and occupancy. The trichomorphometry of the mountain ungulates that has been described may also be very useful in studies undertaken to determine predator-prey relationships. 
Figure 2:- Hair characteristics (cuticular and medullary) of five large wild herbivores of Chang Chenmo Valley, Changthang Wildlife Sanctuary, Ladakh, India

(200


Figure 3:- A three-dimensional scatter-plot showing the clear distinction between values of three hair parameters HT, MT and MI) of the five large wild herbivore species of Chang Chenmo Valley, Changthang Wildlife Sanctuary, Ladakh, India.
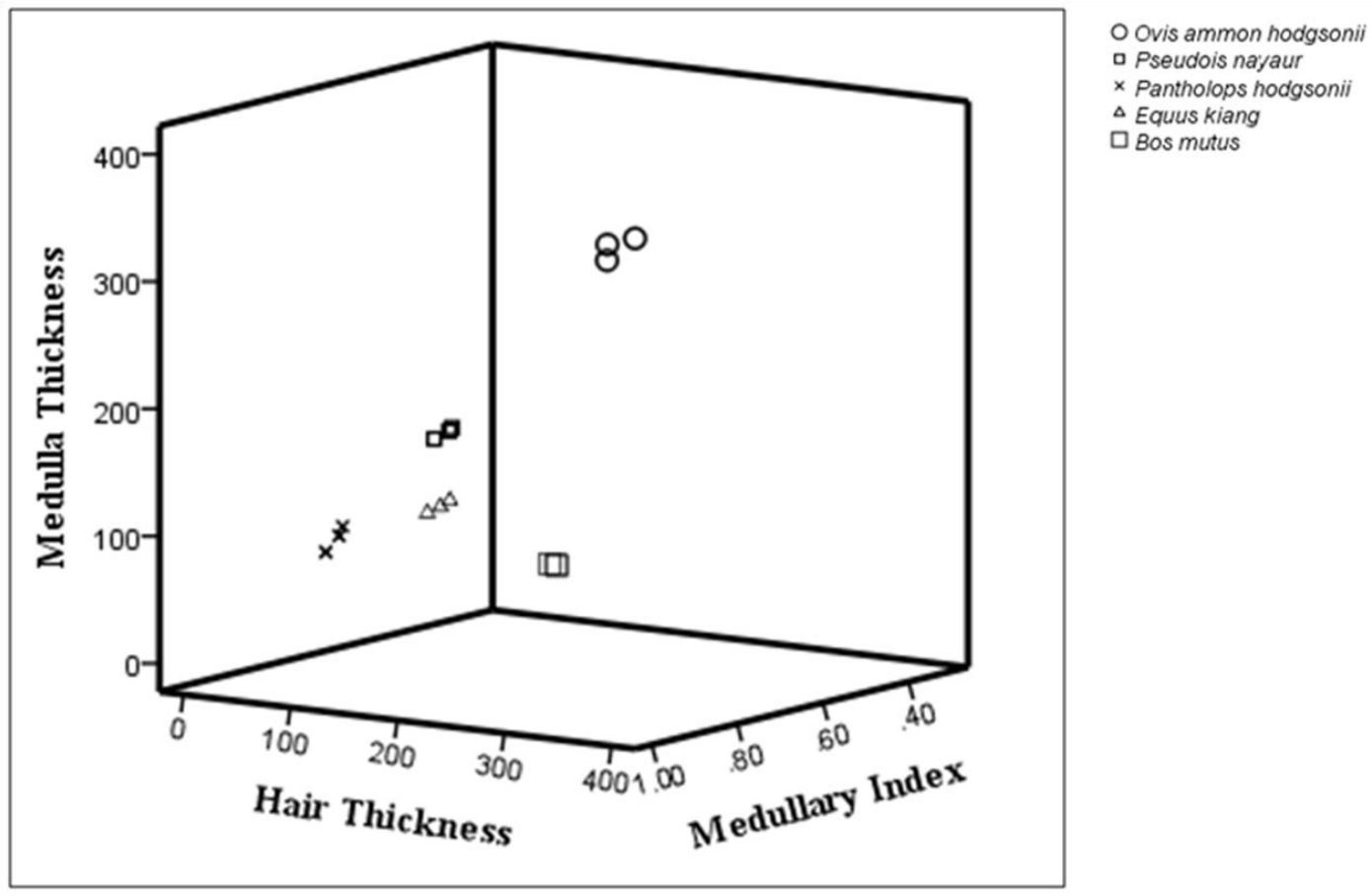

Table 1:- List of large wild herbivores of Chang Chenmo Valley, Changthang Wildlife Sanctuary, Ladakh, with their conservation status

\begin{tabular}{|l|l|l|l|l|l|}
\hline S.No. & English Name & Scientific Name & \multicolumn{4}{|l|}{ Conservation status } \\
\cline { 3 - 6 } & & IUCN & CITES & WPA, 1972 \\
\hline 1. & Tibetan Antelope or Chiru & Pantholops hodgsonii (Abel, 1826) & EN & App.-I & Sch.-I \\
\hline 2. & Blue Sheep or Bharal & Pseudois nayaur (Hodgson, 1833) & LC & App.-III & Sch.-I \\
\hline 3. & Tibetan Argali & $\begin{array}{l}\text { Ovis ammon hodgsonii (Blyth, NT } \\
1841)\end{array}$ & App.-I & Sch.-I \\
\hline 4. & Wild Yak & Bos mutus (Przewalski, 1883) & VU & App.-I & Sch.-I \\
\hline 5. & Tibetan Wild Ass & Equus kiang (Moorcroft, 1841) & LC & App.-II & Sch.-I \\
\hline
\end{tabular}

Table 2:- Relative frequency of occurrence of hair of large wild herbivore species in randomly collected hair samples ( $\mathrm{n}=39)$ during survey in the Chang Chenmo Valley, Ladakh

\begin{tabular}{|l|l|}
\hline Species & \% occurrence of species \\
\hline P. hodgsonii & 10.3 \\
\hline P. nayaur & 5.1 \\
\hline O.a. hodgsonii & 7.7 \\
\hline B. mutus & 2.6 \\
\hline E. kiang & 74.4 \\
\hline
\end{tabular}

$\$$ IUCN - International Union for Conservation of Nature and Natural Resources; CITES - Convention on International Trade in Endangered Species of Wild Flora and Fauna; WPA - Wildlife (Protection) Act, 1972; EN Endangered; LC - Least Concern; NT - Near Threatened; VU - Vulnerable; App. - Appendix; Sch.-Schedule 
Table 3:- Tricho-morphometrics of large wild herbivore species encountered in the Chang Chenmo Valley region, Changthang Wildlife Sanctuary, Ladakh

\begin{tabular}{|c|c|c|c|c|c|}
\hline & \multicolumn{5}{|l|}{ Species } \\
\hline & $\begin{array}{l}\text { Pantholops } \\
\text { hodgsonii }\end{array}$ & Pseudois nayaur & \begin{tabular}{|l|} 
Ovis \\
hodgsonii
\end{tabular} & Bos mutus & Equus kiang \\
\hline \multicolumn{6}{|c|}{ (a) Qualitative hair characteristics } \\
\hline \multicolumn{6}{|c|}{\begin{tabular}{|l|} 
Macroscopic \\
\end{tabular}} \\
\hline Hair colour & Light tan & White & Greyish white & Black & $\begin{array}{l}\text { Brown and muddy } \\
\text { white }\end{array}$ \\
\hline Hair shape & $\begin{array}{l}\text { Short and wavy } \\
\text { with undulations } \\
\text { and kinks }\end{array}$ & Long with kinks & Long with kinks & Long and straigh & thong and straight \\
\hline Hair texture & Soft & Soft and smooth & Rough & Rough & Soft \\
\hline \multicolumn{6}{|l|}{ Microscopic } \\
\hline \multicolumn{6}{|l|}{ Hair cuticle } \\
\hline Scale margin & Smooth & Smooth & Smooth & Crenate & Smooth \\
\hline Scale distance & Distant & Distant & Near & Near & Near \\
\hline Scale pattern & Regular mosaic & Regular wave & Regular wave & Irregular wave & Regular wave \\
\hline \multicolumn{6}{|l|}{ Hair medulla } \\
\hline $\begin{array}{l}\text { Medullary } \\
\text { pattern }\end{array}$ & $\begin{array}{l}\text { Wide cellular } \\
\text { lattice }\end{array}$ & cellular & medullary & $\begin{array}{l}\text { Narrow an } \\
\text { simple medulla }\end{array}$ & $\begin{array}{l}\text { d Wide } \\
\text { lattice }\end{array}$ \\
\hline \multicolumn{6}{|c|}{ (b) Quantitative hair characteristics (in $\mu \mathrm{m})($ mean $\pm \mathrm{SE})$} \\
\hline HT & $109.670 \pm 6.741$ & $208.00 \pm 3.606$ & $374.33 \pm 6.741$ & $90.33 \pm 1.202$ & $149.67 \pm 4.333$ \\
\hline MT & $105.000 \pm 7.000$ & $197.00 \pm 2.646$ & $360.33 \pm 5.783$ & $36.00 \pm 1.155$ & $122.00 \pm 2.887$ \\
\hline MI & $0.960 \pm 0.005$ & $0.95 \pm 0.004$ & $0.96 \pm 0.008$ & $0.40 \pm 0.008$ & $0.82 \pm 0.004$ \\
\hline
\end{tabular}

\section{Acknowledgements:-}

The authors are are deeply indebted to Dr. Tej Partap, Vice Chancellor, and Dr. Shafiq A. Wani, Director Research, Sher-e-Kashmir University of Agricultural Sciences and Technology of Kashmir (SKUAST-Kashmir) for their support, help and cooperation. The support and cooperation of Shri Jigmet Takpa, IFS, Chief Conservator of Forests (Wildlife)/Regional Wildlife Warden, Ladakh Region, Leh, and Mr. Intisar Suhail, Wildlife Warden, Leh, are gratefully acknowledged. The support provided by the former Chief Wildlife Warden, Shri A.K. Singh, and the Chief Wildlife Warden, Shri Deepak Khana, the Chief Wildlife Warden, in the form of the necessary permission for carrying out the study is acknowledged. The kind support provided by Dr. V. B. Mathur, Director, Wildlife Institute of India, and Dr. P.K. Mathur, Dean, Faculty of Wildlife Sciences, for laboratory work at the Forensic Facility at Wildlife Institute of India is sincerely acknowledged. Linguistic editing was performed using Grammarly software (https://app.grammarly.com/).

\section{References:-}

1. Alfred, J.R.B., Julka, J.M., Mehta, H.S., Sharma, R.M., Tak, P.C., Sharma, D.K. and Paliwal, R. (2006). Status Survey of Endangered Species: Status of Kiang Equus kiang Moorcroft, 1841 (Perissodactyla: Equidae) in Eastern Ladakh, India. Zoological Survey of India, Kolkata. ISBN 81-8171-093-2

2. Ashraf, W., Jaffar, M. and Mohammad, D. (1994). Trace metal contamination study on scalp hair of occupationally exposed workers. Bulletin of Environmental Contamination and Toxicology 53: 516-523.

3. Bahuguna, A., Sahajpal, V., Goyal, S.P., Mukherjee, S.K. and Thakur, V. (2010). Identification from Guard Hair of Selected Indian Mammals: A Reference Guide. Wildlife Institute of India, Dehradun, India.

4. Bhatnagar, Y.V., Seth, C.M., Takpa, J., Ul-Haq, S., Namgail, T., Bagchi, S. and Mishra, C. (2007). A strategy for conservation of the Tibetan gazelle Procapra picticaudata in Ladakh. Conservation and Society 5(2). 262-276.

5. Brunner, H. and Coman, B. (1974). The Identification of Mammalian Hair. Inkata Press, Melbourne.

6. Champion, H.G. and Seth, S.K. (1968). A Revised Survey of the Forest Types of India. Manager of Publications, Delhi.

\footnotetext{
${ }^{\S}$ Legend: HT - Hair Thickness, MT - Medulla Thickness, MI - Medullary Index
} 
7. Chane, M. and Yirga, S. (2014). Diversity of medium and large-sized mammals in Borena-Sayint National Park, South Wollo, Ethiopia. International Journal of Sciences: Basic and Applied Research 15(1) 95-106. ISSN 2307-4531

8. Chundawat, R.S. and Qureshi, Q. (1999). Planning Wildlife Conservation in Leh and Kargil Districts of Ladakh. Wildlife Institute of India, Dehradun, India.

9. Dinerstein, E. (2003). The Return of the Unicorns. Columbia University Press, New York. pp-673.

10. Foggin, J.M. (2000). Biodiversity protection and the search for sustainability in Tibetan Plateau grasslands (Qinghai, China). Ph.D. thesis, Arizona State University.

11. Fox, J.L., Nurbu, C. and Chundawat, R.S. (1991). The mountain ungulates of Ladakh, India. Biological Conservation 58: 167-190.

12. Goldstein, M. and Beall, C. (1990). Nomads of Western Tibet: The Survival of a Way of Life. University of California Press, Berkeley, CA.

13. Gordon, I.J., Hester, A.J. and Festa-Bianchet, M. (2004). The management of wild large herbivores to meet economic, conservation and environmental objectives. Journal of Applied Ecology 41(6). 1021-1031.

14. Kondo, K. (2000). The diversity of mammalian pelage. Journal of Faculty of Agriculture Hokkaido University 70: 9-17.

15. Long, R.A., Donovan, T.M., MacKay, P., Zielinski, W.J. and Buzas, J.S. (2011). Predicting carnivore occurrence with noninvasive surveys and occupancy modeling. Landscape Ecology 26: 327-340. DOI 10.1007/s10980-0109547-1

16. Madhusudan, M.D. (2004). Recovery of wild large herbivores following livestock decline in a tropical Indian wildlife reserve. Journal of Applied Ecology 41: 858-869.

17. Mallon, D.P. (1998). Ecology and conservation of mountain ungulates in Ladakh, India. Ph.D. thesis, Department of Biological Sciences, Metropolitan University of Manchester.

18. Meinertzhagen, R. (1927). Ladakh, with special reference to its natural history. The Geographical Journal 70(2). 129-156.

19. Mishra, C. and Humbert-Droz, B. (1998) Avifaunal survey of Tso Moriri Lake and adjoining Nuro Sumdo wetland in Ladakh, Indian Trans-Himalaya. Forktail 14: 865-867.

20. Mishra, C., Wieren, S.E., Heitkonig, I.M.A. and Prins, H.H.T. (2002). A theoretical analysis of competitive exclusion in Trans-Himalayan large herbivore assemblage. Animal Conservation 5: 251-258.

21. Namgail, T. (2009). Mountain ungulates of the Trans-Himalayan region of Ladakh, India. International Journal of Wilderness 15(2). 35-40.

22. Namgail, T., Wieren, S.E., Mishra, C. and Prins H.H.T. (2010). Multi-spatial co-distribution of the endangered Ladakh urial and blue sheep in the arid Trans-Himalayan mountains. Journal of Arid Environments 74: 11621169.

23. O'Connell T.C. and Hedges, R.E.M. (1999). Isotopic comparison of hair and bone: Archaeological analyses. Journal of Archaeological Science 26: 661-665.

24. Olff, H., Ritchie, M.E. and Prins, H.H.T. (2002). Global environmental controls of diversity in large herbivores. Nature 415: 901-904.

25. Owen-Smith, N (1998). Megaherbivores: The Influence of Very Large Body Size on Ecology. Cambridge University Press, Cambridge.

26. Prins, H.H.T. (2000). Competition between wildlife and livestock in Africa. In: Wildlife Conservation by Sustainable Use (eds. Prins HHT, Grootenhuis JG and Dolan TT) Kluwer Academic Publishers, Boston, MA. pp. 51-80.

27. Quadros, J. and Monteiro, E.L.D. (2006). Collecting and preparing mammal hairs for identification with optical microscopy. Revista Brasileira de Zoologia 23: 274-278.

28. Ricklefs, R.E. and Schluter, D. (1993). Species Diversity in Ecological Communities. University of Chicago Press, Chicago.

29. Ripple, W.J., Newsome, T.M., Wolf, C., Dirzo, R., Everatt, K.T., Galetti, M., Hayward, M.W., Kerley, G.I.H., Levi, T., Lindsey, P.A., Macdonald, D.W., Malhi, Y., Painter, L.E., Sandom, C.J., Terborgh, J. and Van Valkenburgh, B. (2015). Collapse of the world's largest herbivores. Science Advances 1. doi:10.1126/sciadv.1400103

30. Rodgers, W.A., Panwar, H.S. and Mathur, V.B. (2000). Wildlife Protected Area Network in India: A Review. Wildlife Institute of India, Dehradun, India.

31. Sahajpal, V., Goyal, S.P., Thakar, M.K. and Jayapal, R. (2009). Microscopic hair characteristics of a few bovid species listed under Schedule I of Wildlife (Protection) Act, 1972 of India. Forensic Science International 189: 34-45. 
32. Sarkar, P., Takpa, J., Ahmed, R., Tiwari, S.K., Pendharkar, A., Saleem-ul-Haq, Miandad, J., Upadhyay, A. and Kaul, R. (2008). Mountain Migrants: Survey of Tibetan Antelope (Pantholops hodgsonii) and Wild Yak (Bos grunniens) in Ladakh, Jammu \& Kashmir, India. Report: 9-52. Department of Wildlife Protection, Jammu and Kashmir Government, IFAW, Widlife Trust of India, 10 Years of Nature, Environment and Ecology Cell, Indian Army, Indo Tibetan Border Police Force.

33. Schaller, G.B. (1998). Wildlife of the Tibetan Steppe. Chicago University Press, Chicago, USA.

34. Shawl, T. and Takpa, J. (2009). Status and Distribution of Tibetan Antelope (Chiru) and Associated Mammals in Changchenmo Valley and Daulat Beg Oldi, Ladakh, India. Department of Wildlife Protection, Government of Jammu and Kashmir.

35. Shawl, T., Takpa, J., Hilaluddin and Namgail, T. (2011). Distribution and encounter rates of large herbivores in Chang Chenmo and Daulat Beg Oldi, Ladakh, Jammu and Kashmir, India. Our Nature 9: 55-60.

36. Taru, P., Mukwada, G. and Chingombe, Z. (2013). Microscopic hair characteristics of South African blue wildebeest (Connochaetes taurinus), lack wildebeest (Connochaetes gnou) and red rock hare (Pronolagus crassicaudatus). Journal of Life Science 5(2). 123-126.

37. Vinod, T.R. and Sathyakumar, S. (1999). Ecology and Conservation of Mountain Ungulates in Great Himalayan National Park, Western Himalaya. Final Report (FREEP-GHNP). Volume 3. Wildlife Institute of India, Dehradun, India.

38. White, C.D. (1993). Isotopic determination of seasonality in diet and death from Nubian mummy hair. Journal of Archaeological Science 20: 657-666.

39. Zeng, C., Wu, J. and Zhang, X. (2015). Effects of grazing on above-vs.below-ground biomass allocation of alpine grasslands on the northern Tibetan Plateau. PLOS ONE 10(8). 1-15. doi:10.1371/journal.pone.0135173. 